\title{
FORMULATION AND EVALUATION OF PROCHLORPERAZINE MALEATE SUSTAINED RELEASE FLOATING TABLET
}

\author{
AHMED ABDULAMEER ALBADRY'1, WEDAD K. ALI' ${ }^{1}$, FOUAD A. AL-SAADY² \\ ${ }^{1}$ Department of Pharmaceutics, College of Pharmacy, Al-Mustansiriya University, Baghdad, Iraq, ${ }^{2}$ Department of Pharmaceutical \\ Chemistry, College of Pharmacy, Al-Mustansiriya University, Baghdad, Iraq \\ Email: ahmedalbadryaaa@yahoo.com \\ Received: 13 Oct 2016 Revised and Accepted: 07 Dec 2016
}

\section{ABSTRACT}

Objective: The objective of this study was to formulate once daily sustained oral release floating tablet of prochlorperazine maleate, this floating tablet has many advantages like reduction in dosing frequency, increase bioavailability, enhance patient compliance, and improve drug solubility

Methods: The prochlorperazine maleate floating tablets were formulated by using hydrophilic swellable polymer and gas generating agent. In this study, 15 formulas were prepared with many variables in order to achieve an optimum dissolution and floating behaviour for the floating tablet. The all prepared formulas were tested for bulk density, tap density, angle of repose, Carr's Index, thickness, weight variation, hardness, friability, drug content, in vitro dissolution test, in vitro buoyancy, and swelling index.

Results: Formula (F2) that contain 55\% (w/w) hydroxypropyl methylcellulose k4M (HPMCK4M), $5 \%(w / w)$ sodium bicarbonate $\left(\mathrm{NaHCO}_{3}\right)$ have acceptable flow properties and compressibility index and good physical properties with floating lag time (16 \pm 0.57$)$ seconds and total floating time $(32 \pm 0.29) \mathrm{h}$ with $100 \%$ release of prochlorperazine maleate at the end of $24 \mathrm{~h}$. Fourier transform infrared spectroscopy (FTIR) study of optimum formula (F2) showed no chemical interaction between the drug and the excipients that used in the formula.

Conclusion: It can be concluded that that the selected formula (F2) can be a promising formula for the preparation of gastro retentive floating drug delivery systems of prochlorperazine maleate.

Keywords: Prochlorperazine maleate, Floating tablet, Sustained release, Hydroxypropyl Methylcellulose k4M (HPMCK4M), Sodium bicarbonate $\left(\mathrm{NaHCO}_{3}\right)$

(C) 2017 The Authors. Published by Innovare Academic Sciences Pvt Ltd. This is an open access article under the CC BY license (http://creativecommons.org/licenses/by/4. 0// DOI: http://dx.doi.org/10.22159/ijpps.2017v9i2.15665

\section{INTRODUCTION}

Oral route of drug administration for the majority of therapeutic applications remains the most favored preference with obvious benefits including ease of administration, flexibility in formulation and patient compliance [1].

Effective oral drug delivery may depend upon the factors such as gastric emptying process, drug release from the dosage form, gastrointestinal transit time and site of drugs absorption [2]. An important factor for a complete drug absorption in the gastrointestinal tract (GIT) is the transition time of the dosage form [3]. Incomplete drug release from the drug delivery system may result from the relatively short gastric emptying time (GET) in humans which is normally about $2-3 \mathrm{~h}$, leading to reduced administered dose efficacy [4]. The easily absorbed drugs from the gastrointestinal tract (GIT) and drugs show short half-life are eliminated rapidly from the systemic circulation [5]. To overcome this physiological problem, many types of research and patent literature illustrated attempts of creating new dosage forms that are able to prolong the time that required for the dosage form to leave the stomach [6]

Floating drug delivery systems are low-density systems which have the adequate buoyancy to float above the gastric contents and stay for a long period of time in the stomach without affecting the gastric emptying rate" [7]

While the system is floating on the gastric contents, the drug is gradually released from the system at the desired rate and the residual system is emptied out of the stomach. This cause an increased gastric residence time (GRT) and preferable control of the fluctuations in plasma drug concentration [8]. Prolonged gastric retention dosage form improves bioavailability, improves solubility for drugs that are less soluble in a high $\mathrm{pH}$ environment (e. g. cinnarizine and chlordiazepoxide), and reduces drug waste [9].
Prochlorperazine, a phenothiazine derivative; it is known as typical antipsychotic medication, whose effect through blocking dopamine receptors. Prochlorperazine and its salts are in general utilised in the avoidance and treating of nausea and vomiting resultant of radiotherapy, chemotherapy, surgery and acute migraine [10]. The half-life of prochlorperazine maleate is 4 to $8 \mathrm{~h}$ and has about $12.5 \%$ oral bioavailability [11].

The aim of the study was to prepare once daily sustained release of prochlorperazine maleate effervescent floating matrix tablet in an attempt to improve drug solubility, bioavailability and patient compliance.

\section{MATERIALS AND METHODS}

\section{Materials}

Prochlorperazine maleate was obtained from Furat pharmaceutical industries (Iraq), hydroxypropyl methyl cellulose (HPMC) HPMCK4M, HPMCK15M, HPMCK100M, carbopol 934, carbopol 940, avicel PH 101 (MCC) were obtained from Jiangsu yew pharmaceutical co. limited (china), sodium bicarbonate $\left(\mathrm{NaHCO}_{3}\right)$ was obtained from Samara drug industry (Iraq), spray dried lactose, talc, magnesium stearate was obtained from Middle east laboratories co limited (Iraq); mannitol was obtained from Provizerpharma (India).

\section{Methods}

Formulation of prochlorperazine maleate floating tablet

Different formulas (15 formulas) of prochlorperazine maleate floating tablets were formulated as shown in the table (1). All formulas were compressed into tablets using direct compression method. The previously weighted ingredients (the drug, polymer, diluent and gas generating agent) were passed through sieve 
(No.45) together and blended for $15 \mathrm{~min}$ in order to achieve a homogenous mixture of powder blend. Then a known weight of the blended powders of different ingredients was mixed with a calculated amount of talc and magnesium stearate powder for $3 \mathrm{~min}$ then compressed to tablet by using $9 \mathrm{~mm}$ biconcave punch tablet machine [12].

Table 1: Composition of different formulas of prochlorperzine maleate floating tablets

\begin{tabular}{|c|c|c|c|c|c|c|c|c|c|}
\hline Ingredient(mg) & F1 & F2 & F3 & F4 & F5 & F6 & F7 & F8 & F9 \\
\hline Prochlorperazine maleate & 15 & 15 & 15 & 15 & 15 & 15 & 15 & 15 & 15 \\
\hline НРМСК4М & 90 & 110 & 130 & - & - & - & - & - & - \\
\hline НРМСК15M & - & - & - & 90 & 110 & 130 & - & - & - \\
\hline HРМСK100M & - & - & - & - & - & - & 90 & 110 & 130 \\
\hline Carbopol 934 & - & - & - & - & - & - & - & - & - \\
\hline Carbopol 940 & - & - & - & - & - & - & - & - & - \\
\hline $\mathrm{NaHCO}_{3}$ & 10 & 10 & 10 & 10 & 10 & 10 & 10 & 10 & 10 \\
\hline AvicelPH 101 (MCC) & 82 & 62 & 42 & 82 & 62 & 42 & 82 & 62 & 42 \\
\hline Spray dried lactose & - & - & - & - & - & - & - & - & - \\
\hline Mannitol & - & - & - & - & - & - & - & - & - \\
\hline magnesium Stearate & 2 & 2 & 2 & 2 & 2 & 2 & 2 & 2 & 2 \\
\hline Talc & 1 & 1 & 1 & 1 & 1 & 1 & 1 & 1 & 1 \\
\hline Total weight (mg) & 200 & 200 & 200 & 200 & 200 & 200 & 200 & 200 & 200 \\
\hline
\end{tabular}

\begin{tabular}{|c|c|c|c|c|c|c|}
\hline Ingredients (mg) & F10 & F11 & F12 & F13 & F14 & F15 \\
\hline Prochlorperazine maleate & 15 & 15 & 15 & 15 & 15 & 15 \\
\hline HPMCK4M & - & - & 110 & 110 & 110 & 110 \\
\hline HPMCK15M & - & - & - & - & - & - \\
\hline HPMCK100M & - & - & - & - & - & - \\
\hline Carbopol 934 & 90 & - & - & - & - & - \\
\hline Carbopol 940 & - & 90 & - & - & - & - \\
\hline $\mathrm{NaHCO}_{3}$ & 10 & 10 & 5 & 20 & 10 & 10 \\
\hline Avicel PH 101 (MCC) & 82 & 82 & 67 & 52 & - & - \\
\hline Spray dried lactose & - & - & - & - & 62 & - \\
\hline Mannitol & - & - & - & - & - & 62 \\
\hline magnesium Stearate & 2 & 2 & 2 & 2 & 2 & 2 \\
\hline Talc & 1 & 1 & 1 & 1 & 1 & 1 \\
\hline Total weight (mg) & 200 & 200 & 200 & 200 & 200 & 200 \\
\hline
\end{tabular}

\section{Evaluation parameters}

\section{Pre-compression parameters}

The angle of repose, Bulk density, Tapped density, Carr's compressibility index, Hausner ratio was determined to find the flow of powders during formulation.

\section{Post-compression parameters evaluation}

\section{Thickness test}

The thickness of tablets was determined using vernier caliper. Three tablets from each formula were used, and average values were calculated \pm standard deviation (SD)[13].

\section{Hardness test}

The hardness of the tablets $\left(\mathrm{Kg} / \mathrm{cm}^{2}\right)$ was determined using electrical hardness tester. In which three tablets from each formula were tested and the average reading \pm SD was recorded [14].

\section{Weight variation test}

The weight variation of the prepared floating tablet was determined by weighing twenty prepared floating tablets individually, and then calculate its average weight and comparing the weight of each tablet to the average weight. The prepared floating tablets meets the USP test if no more than 2 prepared tablets are outside the ratio limit and if no tablet differs by double the percentage limit, as shown in the table (2):[15].

Table 2: Weight variation according to the USP

\begin{tabular}{ll}
\hline Average weight of the tablets (mg) & Maximum difference \% allowed \\
\hline $130<$ & 10 \\
$130-324$ & 7.5 \\
$>324$ & 5 \\
\hline
\end{tabular}

\section{Friability test}

Weigh twenty tablets and placed them in the friabilator and the device was rotated at $25 \mathrm{rpm}$ for $(4 \mathrm{~min})$. After revolutions, the tablets then de-dusted and weighed again. The acceptable percentage weight loss or $\%$ friability showl $\%$ be. The percentage friability was determined by using the following formula: [16].

$$
\% \text { Friability }=\left[\frac{\text { initial weight }- \text { final weight }}{\text { initial weight }}\right] * 100
$$

\section{Content uniformity test}

Ten tablets of an equal weight of the prepared tablet were selected and powdering using mortar and pestle. Then powder equivalent to the average weight of the prepared tablet was weighed and dissolved in $\mathrm{HCl}$ solution ( $\mathrm{pH} 1.2)$.

The solution was filtered and about $(1 \mathrm{ml})$ of the filtrate was appropriately diluted and analysed for prochlorperazine maleate content spectrophotometrically at $254 \mathrm{~nm}$ [17]. 
The requirements for content uniformity of the prepared floating tablet are met if the amount of active ingredient in each tablet lies within the range of $85 \%$ to $115 \%$ of the label claim and the standard deviation is less than $6 \%$ [18].

\section{In vitro buoyancy studies}

In vitro buoyancy of the prepared floating tablet was obtained by determine the floating lag time (FLT) and the total floating time (TFT). The test was done by placing the tablet in $100 \mathrm{ml}$ beaker containing $\mathrm{HCl}$ solution ( $\mathrm{pH} 1.2$ ), and the temperature of the medium is maintained at $37 \pm 0.5^{\circ} \mathrm{C}$. The time between the introduction of tablet and its buoyancy in $\mathrm{HCl}$ solution (pH1.2) is the floating lag time, while the time during which the tablet remains buoyant in the solution is the total floating time [19].

\section{Swelling index studies}

The swelling index of tablets was determined by placing the tablets in $100 \mathrm{ml}$ beaker of $\mathrm{HCl}$ solution ( $\mathrm{pH} 1.2)$ and the temperature of the medium is maintained at $37 \pm 0.5^{\circ} \mathrm{C}$. And then after $1,2,3,4$ and $5 \mathrm{~h}$, each beaker containing tablet was withdrawn and blotted with tissue paper to get rid of the excess water and weighed on the analytical balance. The swelling behaviour of the tablet was determined by measuring the difference in weight of the tablet before and after placing it in $\mathrm{HCl}$ solution $(\mathrm{pH} 1.2)$. Swelling index was calculated by utilise the following equation [20].

$$
\text { Swelling index }=\frac{\mathrm{Wt}-\mathrm{W} 0}{\mathrm{~W} 0} \times 100
$$

Where $\mathrm{W}_{\mathrm{t}}$ is the weight of tablet at time $t$, and $\mathrm{W}_{0}$ is the initial weight of the tablet.

\section{In vitro dissolution test}

In vitro dissolution of the prepared prochlorperazine, maleate tablets were performed utilising USP type II apparatus (paddle) at $37 \pm 0.5^{\circ} \mathrm{C}$ in $900 \mathrm{ml}$ dissolution medium $\mathrm{HCl}$ solution (pH1.2) at $50 \mathrm{rpm}$. Five milliliters samples were withdrawn periodically at $(0.25,0.5,0.75,1,2,3$, $4,5,6,8,12,16,20$, and 24) hours intervals and each sample was substituted with an equal volume of new dissolution medium. Then, the withdrawn samples were filtered and analysed spectrophotometrically at $254 \mathrm{~nm}$. Each test was done in triplicate [21].

Variable affecting prochlorperazine maleate behaviour and release from floating tablets: Effect of polymer type

Five different types of polymers; (hydroxypropyl-methylcellulose K4M (HPMCK4M), HPMCK15M, HPMCK100M, Carbopol 934, and Carbopol 940) in different concentration were utilised to study the influence of polymer type on the floating and drug release properties of prochlorperazine maleate floating tablet as in formulas 1 to 11 .

\section{Effect of polymer concentration}

Formulas 1 to 9 were made to study the influence of polymer concentration on the floating properties and drug release of prochlorperazine maleate floating tablet in which formulas 1,2 , and 3 contain HPMCK4M $90 \mathrm{mg}, 110 \mathrm{mg}$, and $130 \mathrm{mg}$ respectively, formula 4, 5, and 6 contain HPMCK15M $90 \mathrm{mg}, 110 \mathrm{mg}$, and $130 \mathrm{mg}$ respectively, formulas 7, 8, and 9 contain HPMCK100M $90 \mathrm{mg}, 110$ $\mathrm{mg}$, and $130 \mathrm{mg}$ respectively.

\section{Effect of the effervescent agent concentration}

Formulas 2, 12, and 13 which contain $10 \mathrm{mg}, 5 \mathrm{mg}$, and $20 \mathrm{mg}$ of sodium bicarbonate $\left(\mathrm{NaHCo}_{3}\right)$ respectively were utilised to study the influence of the concentration of effervescent agent on the release profile and floating properties of floating tablet.

\section{Effect of diluent types}

Formulas 2, 14, and 15 were utilised to study the influence of types of diluent on the release profile and floating properties of floating tablet in which avecil PH 101(MCC) in formula 2 was replaced by Spray dried lactose in formula 14, and by mannitol in formula 15.

\section{Drug-excipients compatibility studies}

Physicochemical compatibility between prochlorperazine maleate and different excipients were tested using fourier transform infrared spectroscopy (FTIR). The pure drug powder (prochlorperazine maleate) and the optimum formula (F2) were analysed individually by using (Shimadzu 8300, Japan) according to potassium bromide disk method. About 2-3 mg sample was mixed with dried IR grade potassium bromide powder and analysed by FTIR spectroscopy at $4000-400 \mathrm{~cm}^{-1}[22]$.

\section{Studies of in vitro drug release kinetic}

The kinetic model had described drug dissolution from solid dosage form where the dissolved amount of drug is a function of test time. In order to determine the precise mechanism of prochlorperazine maleate release from the prepared floating tablets, drug release data was analysed according to first order, Higuchi square root, zero order, and Korsmeyer-Peppas models. The criteria for selecting the most suitable model were chosen on the basis of goodness of fit test. The data were treated for regression analysis utilising MS EXCEL statistical function [23].

\section{Statistical analysis}

All data were presented as mean \pm SD. Statistical analysis was performed by applying GraphPad Prism Version 7 by choosing oneway ANOVA, followed by Tukey's test (pairwise comparisons) at 95\% significance* ${ }^{*}(\mathrm{p}<0.05)$.

\section{RESULTS AND DISCUSSION}

\section{Pre-compression evaluations}

The measured values of angle of repose, bulk density, tapped density, Carr's index and Hausner ratio with their corresponding type of flow for each formula for the prepared powder mixtures are illustrated in table (3).

Table 3: Pre-compression parameters for powder blend

\begin{tabular}{llllll}
$\begin{array}{l}\text { Formula } \\
\text { number }\end{array}$ & $\begin{array}{l}\text { Angle of repose } \\
\text { (Degree) }\end{array}$ & $\begin{array}{l}\text { Bulk density } \\
\text { (g/cm3) }\end{array}$ & $\begin{array}{l}\text { Tapped density } \\
\text { (g/cm3) }\end{array}$ & $\begin{array}{l}\text { Carr's } \\
\text { Index }\end{array}$ \\
\hline F1 & $33.07 \pm 2.31$ & $0.314 \pm 0.02$ & $0.366 \pm 0.02$ & $14.2 \pm 0.99$ \\
F2 & $32.96 \pm 1.64$ & $0.337 \pm 0.01$ & $0.39 \pm 0.02$ & $\begin{array}{l}\text { Hausner } \\
\text { Ratio }\end{array}$ \\
F3 & $37.12 \pm 2.41$ & $0.372 \pm 0.02$ & $0.462 \pm 0.03$ & $13.56 \pm 0.68$ \\
F4 & $36.03 \pm 2.16$ & $0.351 \pm 0.02$ & $0.422 \pm 0.025$ & $16.82 \pm 1.26$ & $1.16 \pm 0.08$ \\
F5 & $31.43 \pm 1.26$ & $0.37 \pm 0.015$ & $0.425 \pm 0.02$ & $12.94 \pm 0.52$ & $1.24 \pm 0.08$ \\
F6 & $32.27 \pm 2.26$ & $0.384 \pm 0.02$ & $0.443 \pm 0.03$ & $13.32 \pm 0.93$ \\
F7 & $28.22 \pm 1.41$ & $0.341 \pm 0.02$ & $0.38 \pm 0.02$ & $10.26 \pm 0.51$ \\
F8 & $29.43 \pm 1.18$ & $0.323 \pm 0.01$ & $0.36 \pm 0.01$ & $10.27 \pm 0.41$ \\
F9 & $32.91 \pm 1.97$ & $0.321 \pm 0.02$ & $0.365 \pm 0.02$ & $12.05 \pm 0.72$ \\
F10 & $41.63 \pm 2.29$ & $0.373 \pm 0.02$ & $0.473 \pm 0.03$ & $21.14 \pm 1.16$ \\
F11 & $43.15 \pm 1.73$ & $0.38 \pm 0.01$ & $0.483 \pm 0.02$ & $21.32 \pm 0.85$ \\
F12 & $32.27 \pm 0.3$ & $0.328 \pm 0.02$ & $0.378 \pm 0.03$ & $13.22 \pm 0.92$ \\
F13 & $38.23 \pm 1.91$ & $0.358 \pm 0.02$ & $0.427 \pm 0.02$ & $16.16 \pm 0.8$ \\
F14 & $43.26 \pm 2.6$ & $0.35 \pm 0.02$ & $0.445 \pm 0.03$ & $21.34 \pm 1.3$ \\
F15 & $36.87 \pm 2.95$ & $0.371 \pm 0.03$ & $0.45 \pm 0.04$ & 1.05 \\
\hline
\end{tabular}

Data represent mean $( \pm S D)(n=3)$ 
The angle of repose of all formulations was between $28.22^{\circ}$ to 43.26 $\circ$, while the result of the Carr's index and Hausner ratio was between $10.26 \%$ to $21.34 \%$, and 1.11 to 1.27 respectively. The results indicated that the prepared powder mixtures have acceptable flow properties and compressibility.

\section{Post-compression evaluations}

The thickness of prepared prochlorperazine maleate tablets was in the range of $(3.82 \pm 0.015$ to $3.89 \pm 0.017 \mathrm{~mm})$ it was found that all prepared tablets had a uniform thickness.

The hardness of prepared floating tablets was in the range of $(3.32 \pm 0.17$ to $6.26 \pm 0.15 \mathrm{~kg} / \mathrm{cm}^{2}$ ) which indicated good mechanical strength.

The total weight loss of the prepared tablets due to friability was found in the range of $(0.186 \%$ to $0.687 \%)$, which indicated to be less than $1 \%$.

The weight variation of prepared floating tablets was in the range of $(198.2 \pm 1.8$ to $200.2 \pm 0.57)$ in which none of the formulas was exceeding the limits of $( \pm 7.5 \%)$ specified by USP.
The content uniformity of the prepared tablets was in the range of $(96.4 \pm 4.3$ to $99.8 \pm 1.76)$, which reveal a good content uniformity. No tablets lie out of the range of $85-115 \%$ of the label claimas shown in the table (4).

\section{Determination of the floating lag time and total floating time}

The results of floating lag time (FLT) and total floating time (TFT) for all the prepared prochlorperazine maleate floating tablet formulas are shown in the table (5).

Most of the prepared floating tablet formulas had acceptable (FLT) and (TFT) due to the presence of the gas generating agent within the formulas, when this agent become in contact with the acidic dissolution media ( $\mathrm{HCl}$ solution, $\mathrm{pH} 1.2$ ) it generates carbon dioxide gas $\left(\mathrm{CO}_{2}\right)$ which entrapped within the gelling layer of the hydrophilic polymer. Furthermore owing to the swelling of the hydrocolloid particle on the surface after exposure to the aqueous gastric fluids, this sequentially results in an increase bulk volume and provides buoyancy to the floating tablet dosage forms [24].

Table 4: Post compression parameter of prochlorperazine maleate floating tablets

\begin{tabular}{|c|c|c|c|c|c|}
\hline $\begin{array}{l}\text { Formula } \\
\text { Number }\end{array}$ & $\begin{array}{l}\text { Thickness } \\
\text { (mm) }\end{array}$ & $\begin{array}{l}\text { Hardness } \\
\left(\mathrm{kg} / \mathrm{cm}^{2}\right)\end{array}$ & $\begin{array}{l}\text { Friability } \\
(\%)\end{array}$ & Weight variation (mg) & $\begin{array}{l}\text { Content uniformity } \\
(\%)\end{array}$ \\
\hline F1 & $3.85 \pm 0.015$ & $3.62 \pm 0.37$ & 0.402 & $199.3 \pm 1.08$ & $98.4 \pm 3.45$ \\
\hline $\mathrm{F} 2$ & $3.86 \pm 0.011$ & $4.01 \pm 0.15$ & 0.387 & $199.4 \pm 0.87$ & $99.2 \pm 2.41$ \\
\hline F3 & $3.86 \pm 0.011$ & $4.16 \pm 0.23$ & 0.377 & $198.9 \pm 1.22$ & $98.5 \pm 3.54$ \\
\hline $\mathrm{F} 4$ & $3.87 \pm 0.015$ & $3.93 \pm 0.35$ & 0.374 & $199.2 \pm 0.99$ & $99.4 \pm 2.12$ \\
\hline F5 & $3.87 \pm 0.02$ & $4.1 \pm 0.2$ & 0.352 & $200.2 \pm 0.57$ & $98.5 \pm 3.13$ \\
\hline F6 & $3.85 \pm 0.036$ & $4.27 \pm 0.15$ & 0.350 & $198.8 \pm 1.45$ & $99 \pm 1.52$ \\
\hline F7 & $3.83 \pm 0.011$ & $5.86 \pm 0.12$ & 0.245 & $198.5 \pm 1.3$ & $98.5 \pm 2.34$ \\
\hline F8 & $3.85 \pm 0.042$ & $6.06 \pm 0.31$ & 0.227 & $199 \pm 0.64$ & $99.6 \pm 1.23$ \\
\hline F9 & $3.82 \pm 0.015$ & $6.13 \pm 0.4$ & 0.186 & $199.1 \pm 0.76$ & $99.8 \pm 1.76$ \\
\hline F10 & $3.88 \pm 0.025$ & $6.26 \pm 0.15$ & 0.235 & $198.5 \pm 1.18$ & $96.4 \pm 4.3$ \\
\hline F11 & $3.89 \pm 0.017$ & $6 \pm 0.25$ & 0.247 & $198.2 \pm 1.8$ & $97.6 \pm 3.62$ \\
\hline F12 & $3.85 \pm 0.04$ & $3.9 \pm 0.26$ & 0.354 & $200 \pm 0.56$ & $97.5 \pm 2.22$ \\
\hline F13 & $3.83 \pm 0.02$ & $3.8 \pm 0.2$ & 0.369 & $198.3 \pm 1.1$ & $99.7 \pm 1.56$ \\
\hline F14 & $3.83 \pm 0.061$ & $3.43 \pm 0.15$ & 0.687 & $198.3 \pm 0.73$ & $96.5 \pm 4.31$ \\
\hline F15 & $3.83 \pm 0.045$ & $3.32 \pm 0.17$ & 0.602 & $199.1 \pm 0.83$ & $98 \pm 4.21$ \\
\hline
\end{tabular}

Data represent mean $( \pm S D)(n=3)$

Table 5: Floating lag time and total floating time

\begin{tabular}{lll}
\hline Formula number & Floating lag time (seconds) & Total floating time (H) \\
\hline F1 & $8 \pm 0.57$ & $26 \pm 0.28$ \\
F2 & $16 \pm 0.57$ & $32 \pm 0.29$ \\
F3 & $130 \pm 3.51$ & $45 \pm 2.08$ \\
F4 & $10 \pm 1$ & $28 \pm 0.87$ \\
F5 & $19 \pm 1.53$ & $33 \pm 1.76$ \\
F6 & $142 \pm 7.76$ & $47 \pm 0.50$ \\
F7 & $23 \pm 1.53$ & $44 \pm 0.87$ \\
F8 & $257 \pm 4.16$ & $64 \pm 1.42$ \\
F9 & $298 \pm 7.64$ & $66 \pm 2.15$ \\
F10 & Not float & Not float \\
F11 & Not float & Not float \\
F12 & $568 \pm 6.81$ & $45 \pm 1.53$ \\
F13 & $4 \pm 0.58$ & $26 \pm 0.88$ \\
F14 & $8 \pm 1.53$ & $31 \pm 2.08$ \\
F15 & $6 \pm 0.58$ & $27 \pm 1.53$ \\
\hline
\end{tabular}

Data represent mean $( \pm \mathrm{SD})(\mathrm{n}=3)$

The floating lag time and total floating time are prolonged with increase Hydroxypropyl methylcellulose (HPMC) concentration and viscosity. An increase in lag time can be attributed to increases tablet integrity and formation of a stronger gel layer with increasing the polymer concentration and/or viscosity, thus more time is required to hydrate the tablet. Additionally, as the polymer concentration and/or viscosity increased, the tablet can retain $\mathrm{CO}_{2}$ for a longer period of time and thus shows longer floating time periods [25]. On the other hand, the formulas that are containing Carbopol 934 and Carbopol 940 (F10and F11 respectively) did not float due to high carbopol affinity towards water, which promotes penetration of water into floating tablet matrices, leading to increased tablet density and hence decrease in its floating capacity [26].

It was found that as the concentration of sodium bicarbonate $\left(\mathrm{NaHCO}_{3}\right)$ increased, the floating lag time and total floating time decreased this behavior can be attributed to the fact that as amount of $\mathrm{NaHCO}_{3}$ increases the result of effervescence amount increases too, which in turn causes pore formation, and that led to rapid hydration of the HPMCK4M polymer matrix and therefore cause decrease tablet floating time [27]. 
The effect of diluent type on floating properties found that formula 2 which contain avicel Ph101(MCC) showed longer floating lag time and total floating time than F14 which contains spry dried lactose (SDL) and this show longer floating lag time and total floating time than F15 which contains (mannitol) due to that both lactose and mannitol are water soluble in nature, while MMC is hydrophobic in nature, this property accelerates the penetration of dissolution medium to matrix lead to floatation of the prepared floating tablet in a short period of time [28].

\section{Determination of the swelling index of the floating tablets}

The swelling index of the prepared tablet is calculated with respect of time. As the time increase the swelling index of the prepared tablet increase. Because the weight gain of prepared tablet increased proportionally with the rate of hydration. Afterwards, it decreased gradually due to the dissolution of the external gelling layer of the prepared tablet in the dissolution medium [29]. There is a linear relationship between the concentration and viscosity of the polymer and swelling process as shown in the table (6), which illustrate the swelling index of the prepared prochlorperazine maleate floating tablets.

Formulas (10 and 11) was excluded from the study due to bad floating properties.

\section{Drug release}

Fig. (1,2, and 3) show the effect of polymer type on drug release in which as the polymer viscosity increases the rate of drug release was decreased significantly*, This behavior may be elucidated by the relation between the polymer viscosity and the disentanglement concentration (the critical concentration of polymer below which the polymer chains separate and detach from a qualified matrix). The higher polymer viscosity makes greater chain entanglement, so it becomes harder for longer chains to dissolve [30].

This lead to the formation of thicker gel and the ability to hold liberated gas for a longer time, and not allow fast diffusion of the drug from the tablet matrix [31]

Table 6: Study of swelling characteristics of floating tablets of prochlorperazine maleate

\begin{tabular}{|c|c|c|c|c|c|}
\hline \multirow{2}{*}{$\begin{array}{l}\text { Formula } \\
\text { Number }\end{array}$} & \multicolumn{5}{|c|}{ Time in hours (swelling \%) } \\
\hline & 1h. & 2h. & 3h. & 4h. & 5h. \\
\hline F1 & $62.5 \pm 3.2$ & $74 \pm 4.3$ & $83.33 \pm 4.8$ & $92.5 \pm 4.6$ & $85.66 \pm 3.6$ \\
\hline F2 & $85.33 \pm 5.7$ & $98 \pm 4.9$ & $104 \pm 7.5$ & $110.25 \pm 7.4$ & $117 \pm 4.4$ \\
\hline F3 & $100.5 \pm 6.3$ & $107.66 \pm 6.4$ & $111 \pm 6.7$ & $121 \pm 7.3$ & $134.5 \pm 5.6$ \\
\hline F4 & $77.5 \pm 3.1$ & $89 \pm 6.9$ & $96 \pm 5.3$ & $101.33 \pm 4.0$ & $102.5 \pm 4.1$ \\
\hline F5 & $92.5 \pm 6.4$ & $99 \pm 5.5$ & $108 \pm 4.9$ & $115.83 \pm 6.2$ & $127 \pm 7.3$ \\
\hline F6 & $110 \pm 6.1$ & $118.83 \pm 7.6$ & $123.5 \pm 6.7$ & $134 \pm 5.3$ & $139.33 \pm 8.5$ \\
\hline F7 & $109.5 \pm 5.3$ & $113 \pm 4.9$ & $124.5 \pm 7.5$ & $130 \pm 7.5$ & $138.5 \pm 7.3$ \\
\hline F8 & $116.33 \pm 7.3$ & $128 \pm 4.6$ & $136.5 \pm 8.8$ & $142.92 \pm 3.9$ & $149.66 \pm 5.6$ \\
\hline F9 & $120.5 \pm 4.2$ & $131.33 \pm 7.8$ & $139 \pm 6.4$ & $148.5 \pm 5.2$ & $155.58 \pm 8.7$ \\
\hline F12 & $78.58 \pm 3.9$ & $84.5 \pm 5.7$ & $91 \pm 5.8$ & $97.5 \pm 4.8$ & $107.5 \pm 5.7$ \\
\hline F13 & $92.5 \pm 2.8$ & $101.25 \pm 5.3$ & $109 \pm 4.9$ & $101.5 \pm 6.5$ & $96.42 \pm 2.4$ \\
\hline F14 & $67.5 \pm 3.6$ & $76.5 \pm 3.3$ & $87.5 \pm 6.5$ & $91.83 \pm 5.7$ & $84.33 \pm 3.1$ \\
\hline F15 & $62 \pm 3.1$ & $78 \pm 4.2$ & $89.17 \pm 4.4$ & $82.83 \pm 3.1$ & $73 \pm 4.7$ \\
\hline
\end{tabular}

Data represent mean $( \pm S D)(n=3)$

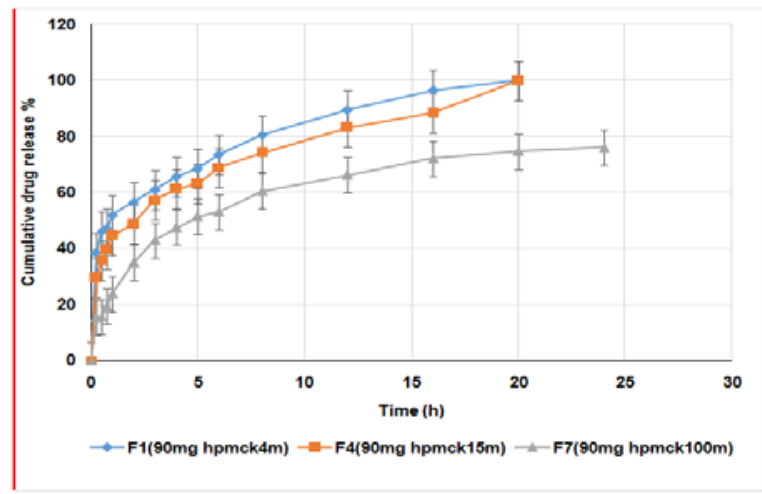

Fig. 1: The effect of polymer type on the release of prochlorperazine maleate floating tablets in $\mathrm{pH} 1.2 \mathrm{HCl}$ solution at $37^{\circ} \mathrm{C}$ temp (use 90 mg polymer concentration), Data represent mean $( \pm S D)(n=3)$

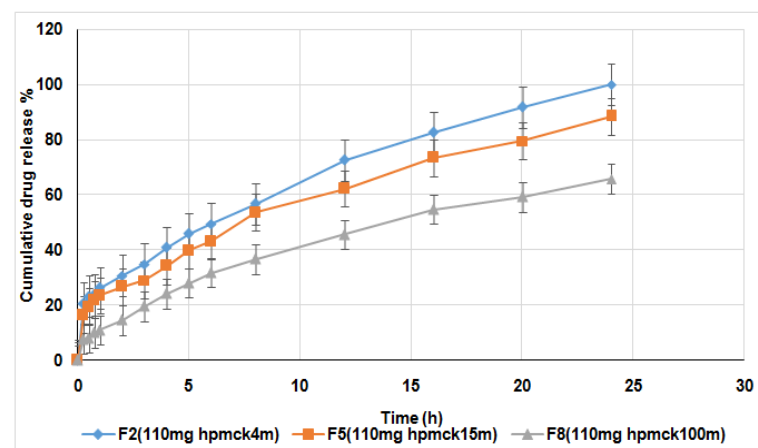

Fig. 2: The effect of polymer type on the release of prochlorperazine maleate floating tablets in $\mathrm{pH} 1.2 \mathrm{HCl}$ solution at $37^{\circ} \mathrm{C}$ (use $110 \mathrm{mg}$ polymer concentration), Data represent mean $( \pm S D)(n=3)$ 


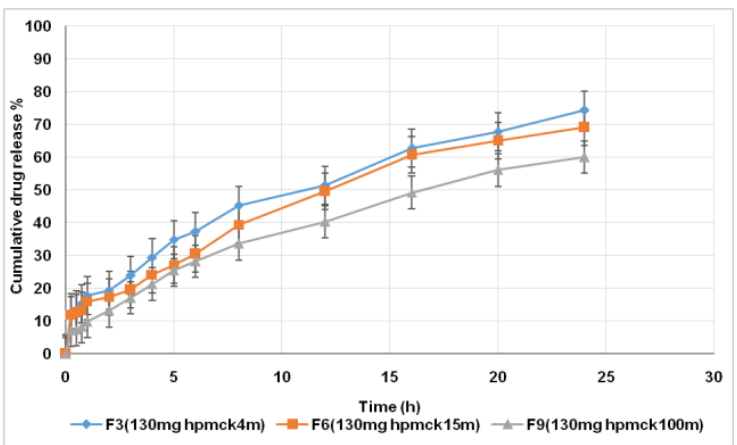

Fig. 3: The effect of polymer type on the release of prochlorperazine maleate floating tablets in pH $1.2 \mathrm{HCl}$ solution at $37^{\circ} \mathrm{C}$ (use $130 \mathrm{mg}$ polymer concentration), Data represent mean $( \pm S D)(n=3)$

While fig. $(4,5$, and 6$)$ shows the effect of polymer concentration on drug release in which as the concentration of polymer in the formula increases, the rate of drug release decrease significantly*, This indirect relationship between polymer concentration and drug release is due to the fact that higher polymer concentration will forming a stronger viscous gel layer that decrease the rate of water diffusion into the floating tablet matrix, which cause decrease drug release [32].

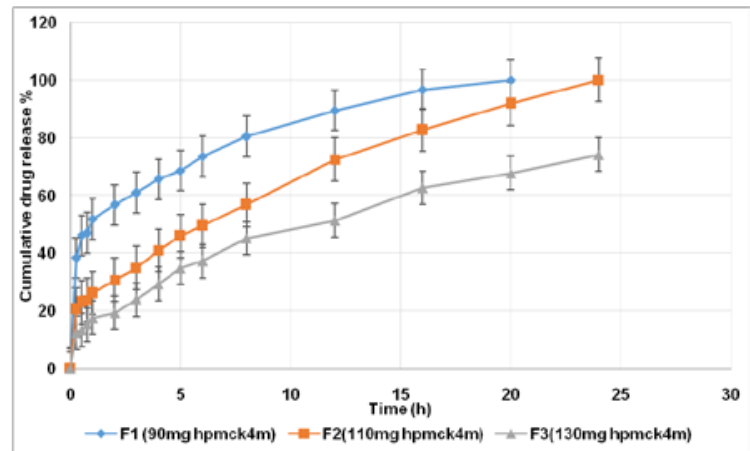

Fig. 4: The effect of HPMC K4M polymer concentration on the release of prochlorperazine maleate floating tablets in $\mathrm{HCl}$ solution pH1.2 at $37^{\circ} \mathrm{C}$, Data represent mean $( \pm \mathrm{SD})(\mathrm{n}=3)$

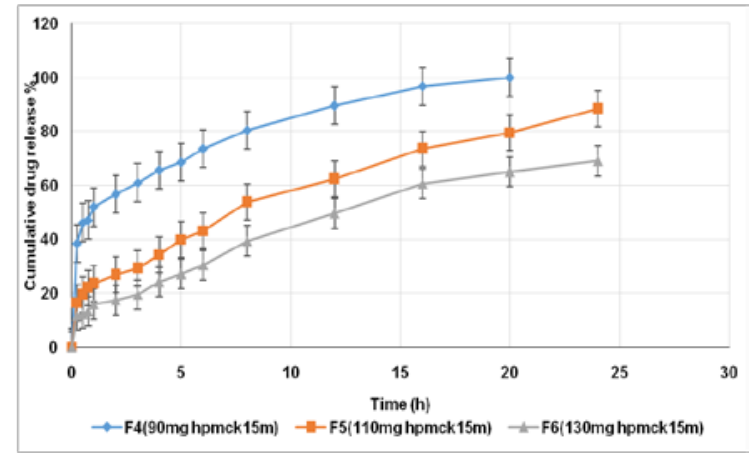

Fig. 5: The effect of HPMC K15M polymer concentration on the release of prochlorperazine maleate floating tablets in HCl solution pH1.2 at $37^{\circ} \mathrm{C}$, Data represent mean $( \pm \mathrm{SD})(\mathrm{n}=3)$

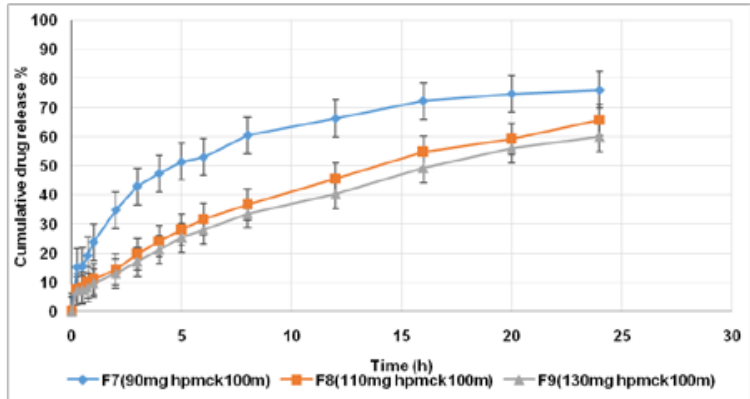

Fig. 6: The effect of HPMC K100M polymer concentration on the release of prochlorperazine maleate floating tablets in $\mathrm{HCl}$ solution pH1.2 at $37^{\circ} \mathrm{C}$, Data represent mean $( \pm S D)(n=3)$ 
The effect of effervescent agent concentration on drug release showed in fig. (7) in which as the concentration of effervescent agent in the formula was increased, the rate of drug release was significantly* increased. This direct relationship was due to the porous nature of the $\mathrm{NaHCO}_{3}$ containing tablet, and also, the high amount of $\mathrm{NaHCO}_{3}$ that created channels for prochlorperazine maleate drug release by increase the pore size of the polymer matrix and increase the pressure of gas inside the polymer matrix [28].

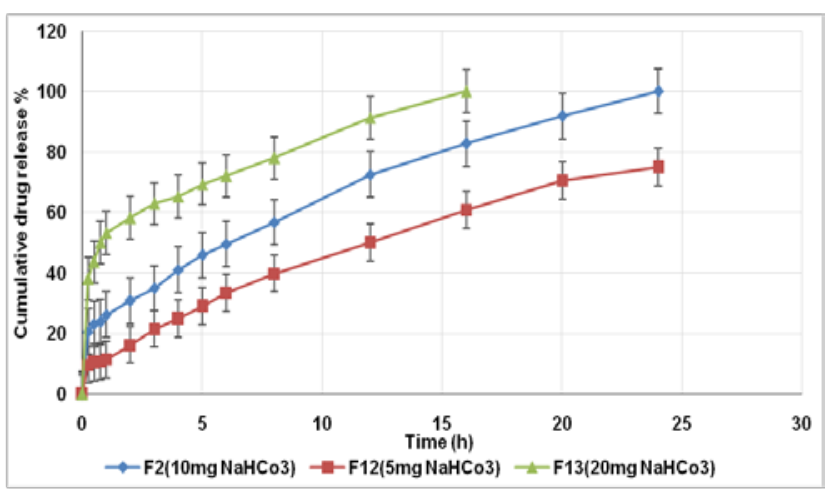

Fig. 7: The effect of sodium bicarbonate concentration on the release of prochlorperazine maleate in $\mathrm{HCl}$ solution pH 1.2 at $37^{\circ} \mathrm{C}$. Data represent mean $( \pm S D)(n=3)$

The in vitro release of prochlorperazine maleate from floating tablet was significantly* increased in F14 and F15 which contain SDL and mannitol respectively in comparison with F2 which contain MCC as shown in fig. (8). These results may be due to that formulas 14 and 15 have a faster rate of hydration than F2 owing to SDL and mannitol higher water solubility than that of MCC.
Alternatively, MCC is a water-swellable and hydrophobic polymer and thus remains swelling for a long time. Thus, it showed larger swelling diameter as compared to those contain lactose and mannitol. On the other hand, lactose and mannitol dissolves and leaves more pores to be filled with water hence results in more water penetration into the matrix [33].

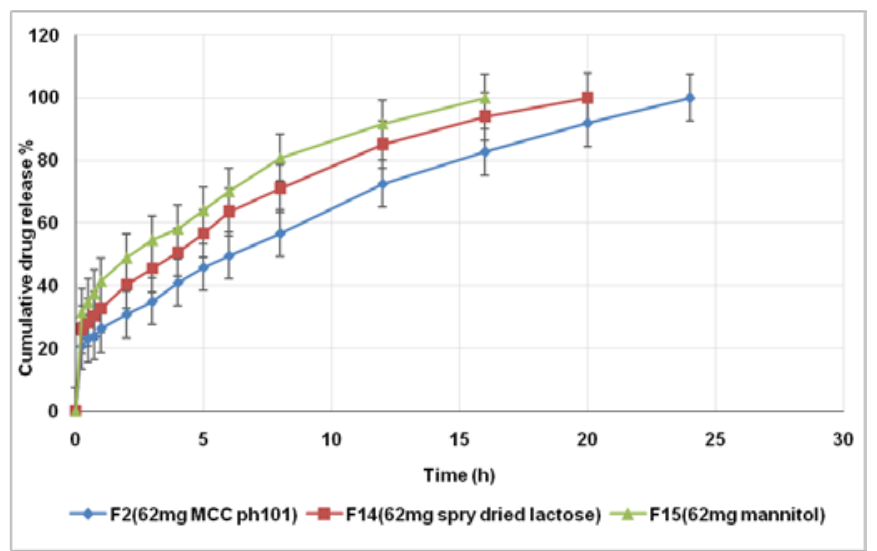

Fig. 8: The effect of diluent type on the release of prochlorperazine maleate floating tablets in solution $\mathrm{HCl} \mathrm{pH1.2}$ at $37^{\circ} \mathrm{C}$, Data represent mean $( \pm S D)(n=3)$

\section{Drug-excipients compatibility studies}

The Fourier transform infrared spectroscopy (FTIR) spectrum for the pure prochlorperazine maleate as shown in fig. (9) displayed band at $3435 \mathrm{~cm}^{-1}$ attributed to the hydroxyl $(\mathrm{OH})$ in the maleate group, while the band $3026 \mathrm{~cm}^{-1}$ assigned to the (C-H) aromatic rings in the backbone of the prochlorperazine. The $(\mathrm{C}-\mathrm{H})$ of aliphatic groups $\left(\mathrm{CH}_{3}\right.$ and $\left.\mathrm{CH}_{2}\right)$ appeared in the expected area for the stretching vibration at $2974 \mathrm{~cm}^{-1}$. The bands appeared at $1693 \mathrm{~cm}^{-}$ 1and1620 $\mathrm{cm}^{-1}$ attributed to the $(\mathrm{C}=0)$ stretching of two carboxylic groups of maleate structure [34].

The band appeared at $1568 \mathrm{~cm}^{-1}$ attributed to $(\mathrm{C}=\mathrm{C})$ of the aromatic ring. The band appeared at $1089 \mathrm{~cm}^{-1}$ attributed to $(\mathrm{C}-\mathrm{Cl})$ stretching in the benzene ring. While the fingerprint area showed the bending bands of the drug.

The FTIR spectrum of prochlorperazine maleate after formulation in floating tablet dosage form as shown in the fig. (10) displayed same functional groups band with small shifting indicating the compatibility and uniformity of excipients with the drug without any chemical modification of the drug.

\section{Determination of the Release Kinetics of optimised formula (F2)}

The drug release data of optimised formula was fitted to models representing first order kinetic, zero order kinetic, Korsmeyerpeppas release kinetic and Higuchi releases kinetic to identify the release mechanisms of the drug.

The data were treated for regression analysis by MS-EXCEL statistical function as shown in the fig. 11, 12, 13, and 14.

The results of the study shows the in vitro release of the drug could be best expressed by Higuchi's equation as the optimised formula showed good linearity (R2: 0.9889) and that indicates the diffusion is a dominant mechanism of drug release with this formula. 


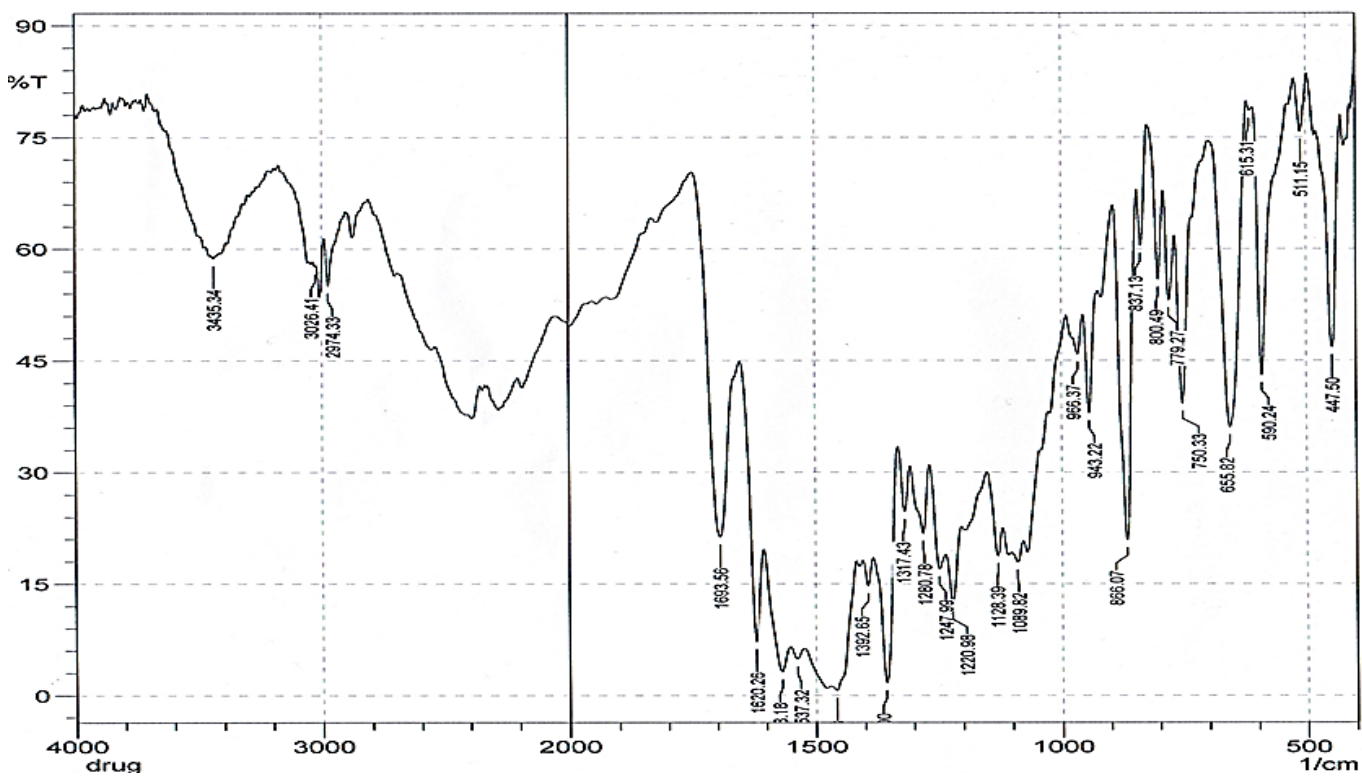

Fig. 9: FTIR spectra of prochlorperazine maleate pure powder

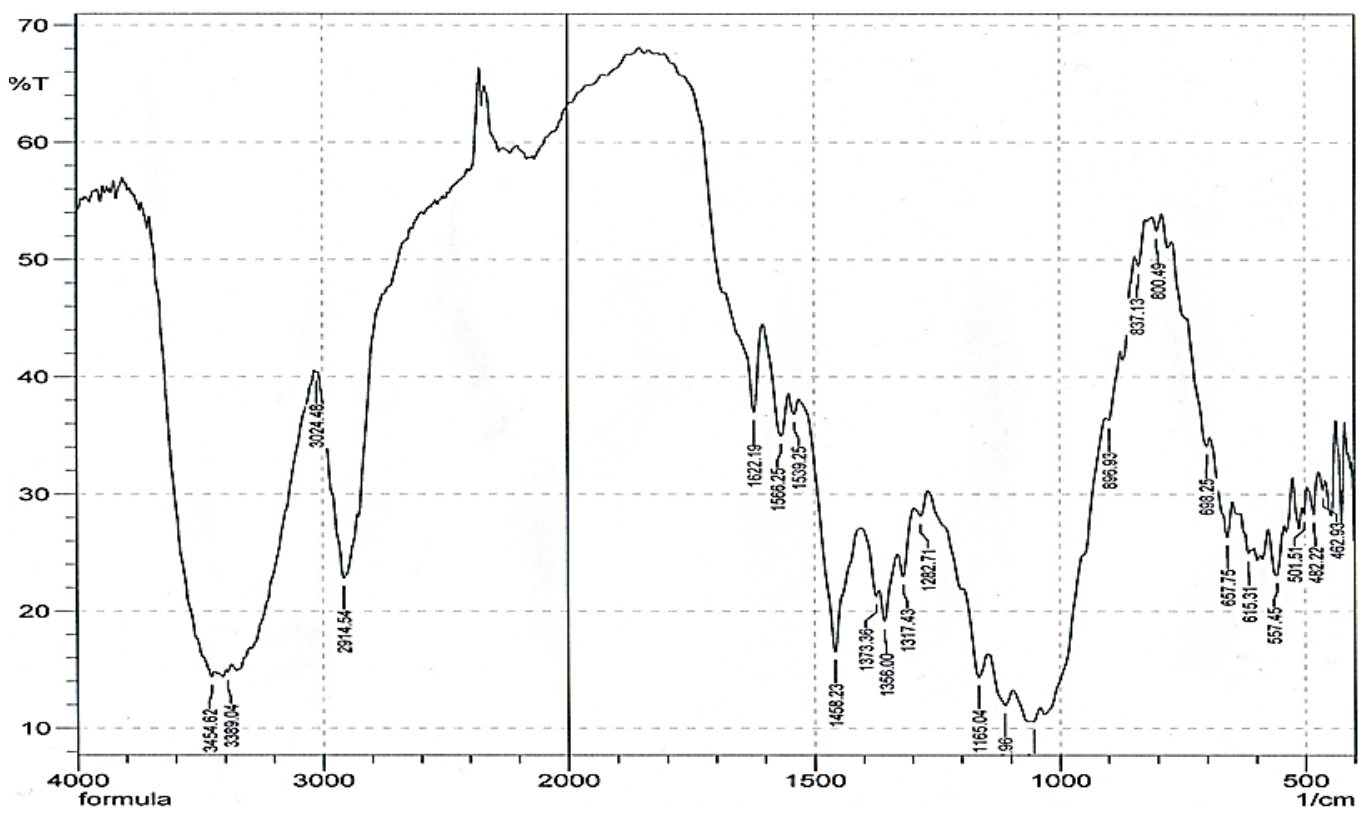

Fig. 10: FTIR spectra of prochlorperazine maleate with physical mixture (F2)

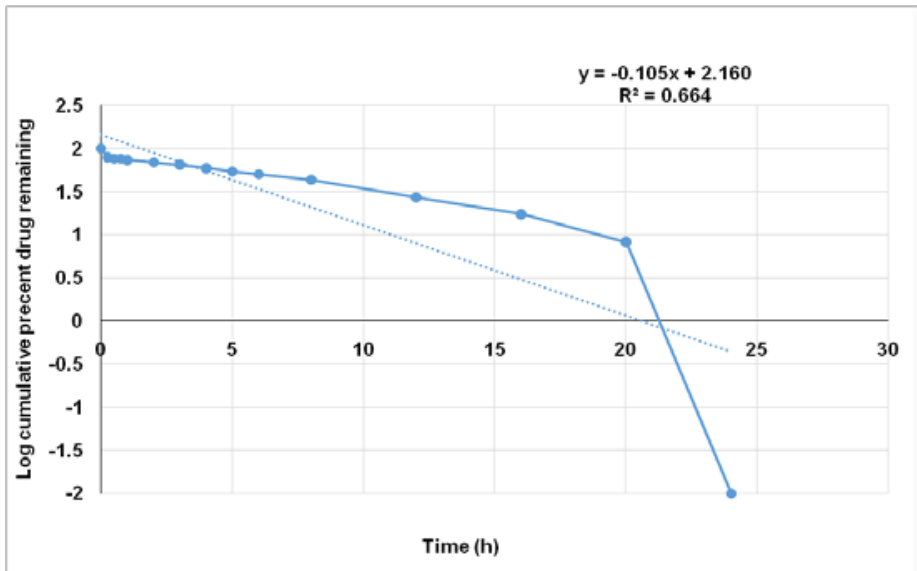

Fig. 11: First order release kinetics of optimised formula (F2) 


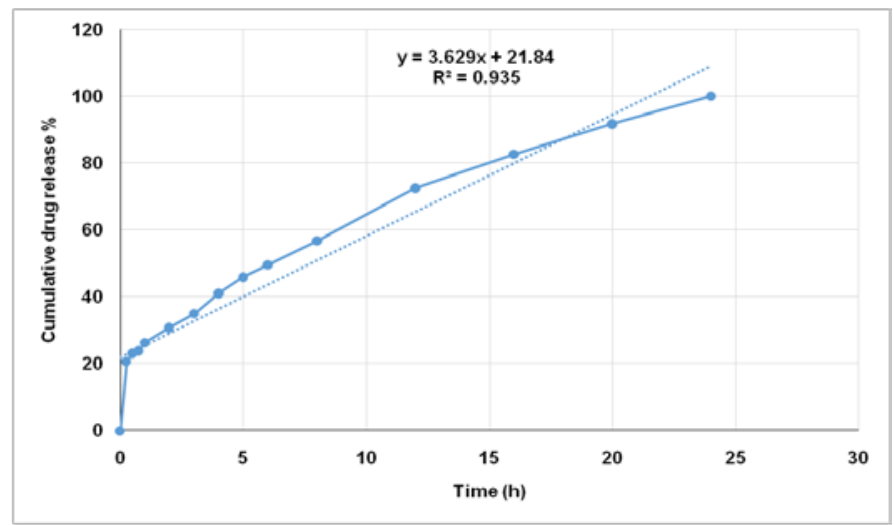

Fig. 12: Zero-order release kinetics of optimised formula (F2)

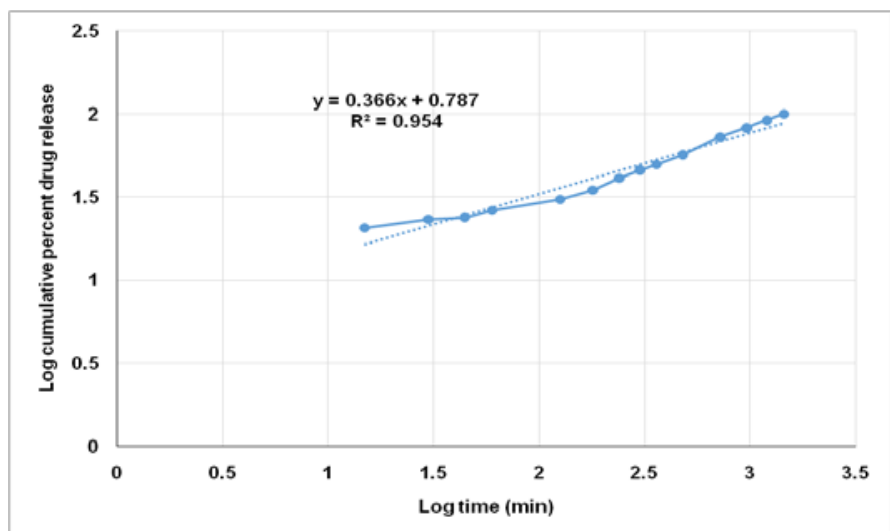

Fig. 13: Korsmeyer-peppers release kinetics of optimised formula (F2)

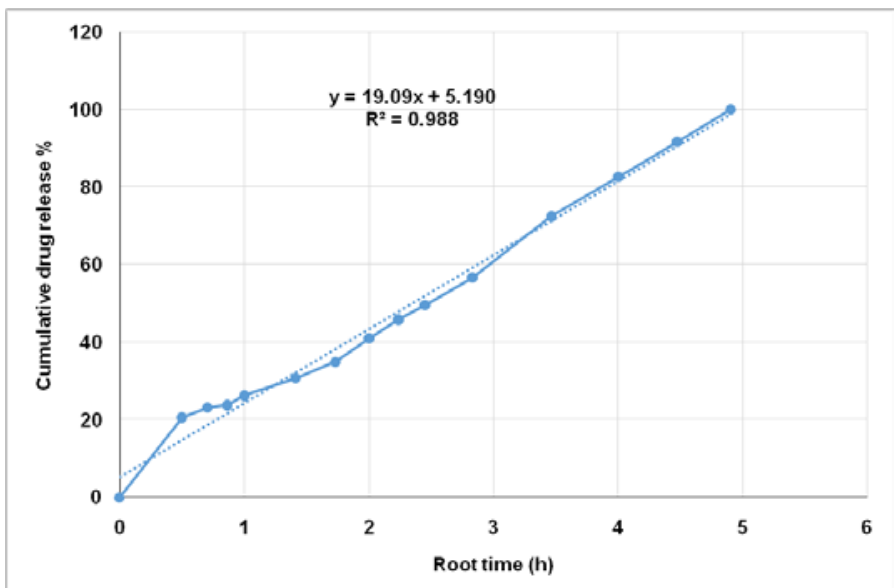

Fig. 14: Higuchi release kinetic of optimised formula (F2)

\section{CONCLUSION}

The formulation of sustained release $(24 \mathrm{~h})$ floating tablet of prochlorperazine maleate $(15 \mathrm{mg})$ was successfully achieved, which can be taken once daily thereby controlling limitations accompanied with ordinary immediate release dosage form of the drug ( $5 \mathrm{mg}$ of prochlorperazine maleate) which taken up 3-4 times daily resulting in an improvement in patient compliance (as the number of giving doses was decreased) and more efficient treatment for prolonged period of time (longer half-life and higher bioavailability).

\section{CONFLICTS OF INTERESTS}

Declared none

\section{REFERENCES}

1. Pahwa R, Kumar S, Saini N, Kumar V. Gelucire mediated gastric floating drug delivery systems. Pharm Lett 2012;4:1038-43.

2. Meenakshi B, Santosh K, Annapurna O. Floating drug delivery system: a review. J Drug Delivery Ther 2014;4:130-4.

3. Ugurlu T, Karacgcek U. An overview on gastro retentive drug delivery systems. J Med Pharm Innovation 2014;1:5-11.

4. Shilpa BC, Vishnu P, Babu KN, Umamaheshwararao V, Sriyanka KS, Sravanii T. A brief review on floating drug delivery system. South Pacific J Pharma Bio Sci 2014;2:137-53.

5. Dwivedi S, Kumar V. Floating drug delivery systems a concept of gastro retention dosages form. Int J Res Pharm Biomed Sci 2011;2:1414-26 
6. Patil KK, Saptarshi D. A review on floating drug delivery system. Int J Pharm Sci Rev Res 2013;21:276-83.

7. Narang N. An updated review on: floating drug delivery system (FDDS). Int J Appl Pharm 2011;3:1-7.

8. Sadiq AAK, Altaii RAJ, Tawfiq FA. Floating drug delivery systems using metronidazole as a model drug part i: by the effervescent method. Al-mustansiriyah. J Pharm Sci 2013;13:36-46.

9. Amit JK, Rammulrajsinh R, Sonali D, Kinal P, Pradeep A. Hydrodynamically balanced systems (HBS): the innovative approach of gastro retention: a review. Int J PharmTech Res 2011;3:1495-508.

10. Badshah A, Subhan F, Shah NH, Bukhari NI, Saeed M, Shah KU. Once daily controlled release matrix tablet of prochlorperazine maleate: influence of ethocel ${ }^{\circledR}$ and/or methocel ${ }^{\circledR}$ on in vitro drug release and bioavailability. Drug Dev Ind Pharm 2012;38:190-9.

11. Rakesh K, Srilatha S, Srinivas N. Formulation and evaluation of prochlorperazine maleate oral dispersible tablets. Int J Adv Pharm Sci 2014;5:2472-7.

12. Madhuri KSN, Suresh SNV, Rao MS. Formulation and evaluation of extended release floating tablets of lamivudine employing different grades of HPMC. Int J Pharm Pharm Sci 2013;5:7016-20.

13. Rahi FA, Thomas LM. Formulation and in vitro evaluation of mucoadhesive antimicrobial vaginal tablets of ciprofloxacin hydrochloride. Al-mustansiriyah. J Pharm Sci 2012;12:200-13

14. Elbary AA, Ramadan AA, Bendas IR, Mostafa DAE. Formulation and evaluation of taste masked rapidly disintegration tablet containing flupentixol dihydro chloride. Int J Pharm 2011;2:58-64.

15. Kumar S, Das M, Gupta KS, Kumar R, Chongdar A, Ghosh LK. Design, development, optimisation and evaluation of gastroretentive floating tablets of atenolol. Scholars Res Library 2013;5:436-56

16. Singh S, Prajapati K, Pathak AK, Mishra A. Formulation and evaluation of floating tablet of captopril. Int J PharmTech Res 2011;3:333-41.

17. Sharma VK. Meloxicam loaded floating sustained release matrix tablet. J Adv Pharm Edu Res 2012;2:18-24.

18. Allen, Loyd V, Popovich, Nicholas G, Ansel, Howard C. Ansel's pharmaceutical dosage forms and drug delivery systems. Ninth Edition. Lippincott Williams and Wilkins; 2011.

19. Kavitha K, Puneeth KP, Tamizh Mani T. Development and evaluation of rosiglitazone maleate floating tablets. Int J Appl Pharm 2010;2:6-10.

20. Rao RK, Lakshmi R. Design, development and evaluation of clopidogrel bisulfate floating tablets. Int J Pharm Invest 2014;4:19-26

21. Marie NK, Mohsen M, Neama M, Zuwar N. Few factors affecting the buoyancy and release of theophylline anhydrous from the hydrodynamically balanced delivery system. Int J Sci Technol 2011;6:85-96

22. Reddy MNK, Hussain MA, Rao TR, Kishna TR, Pavani V. Formulation and evaluation of naproxen oral disintegrating tablets. Int J Pharm Biol Sci 2012;2:303-16

23. Amit P, Kumar JS, Harishanker P, Tarkeshwar S, Arpit S. Formulation development and evaluation of famotidine floating tablet. Int J Sci Technol 2010;4:224-9.

24. Narang N. An updated review on: floating drug delivery (FDDS). Int J Appl Pharm 2011;3:1-7.

25. Srilakshmi P, Koushik KN, Raju SD, Rao RN, Prasanna LJ, Deepthi B. Formulation and evaluation of gastro retentive floating tablets of an antipsychotic drug. Am J PharmTech Res 2014;4:470-6.

26. Iftequar S, Saifee M, Swaroop L, Zaheer Z, Meraj S, khan F, et al. Formulation and evaluation of floating drug delivery system of ramipril. J Innovations Pharm Biol Sci 2016;3:85-95.

27. Lakshmi AP, Kumar GA, Reddy TK, Kumar MA. Development and in-vitro evaluation of gastro retentive verapamil $\mathrm{Hcl}$ floating tablets. Int J Pharm Pharm Sci 2012;4:360-3.

28. Toma NM, Khalil YI. Formulation and evaluation of bilayer tablets containing immediate release aspirin layer and floating clopidogrel layer. Iraqi J Pharm Sci 2013;22:40-9.

29. Krishnarajan D, Manivannan R, Nidhin C, Senthilkmar N. Design and characterisation of floating tablets of ranolazine. Int Res J Pharm 2012;3:268-72.

30. Rahman M, Roy S, Das SC, Jha MK, Begum T, Ahsan Q et al. Evaluation of various grades of hydroxypropylmethylcellulose matrix systems as oral sustained release drug delivery systems. J Pharm Sci Res 2011;3:930-8.

31. Nicole K, Owen IC. Swelling and erosion properties of hydroxypropyl-methylcellulose (Hypromellose) matricesinfluence of agitation rate and dissolution medium composition. Int J Pharm 2004;279:141-52.

32. Soniya C, Manojkumar P, Gorakhnath H, Audmbar M, Santosh J. Formulation and evaluation of floating tablets of nizatidine. Int J Res Ayurveda Pharm 2015;6:290-8.

33. Tukaram NB, Rajagopalan LV, Shartchandra PSI. The effects of lactose, microcrystalline cellulose and dicalcium phosphate on swelling and erosion of compressed HPMC matrix tablets: texture analyser. Iranian J Pharm Res 2010;9:349-58.

34. Shirsand SB, Suresh S, Para MS, Swamy PV. The design of fast disintegrating tablets of prochlorperazine maleate by effervescence method. Indian J Pharm Sci 2009;71:447-51.

\section{How to cite this article}

- Ahmed Abdulameer Albadry, Wedad K Ali, Fouad A AL-Saady Formulation and evaluation of prochlorperazine maleate sustained release floating tablet. Int J Pharm Pharm Sci 2017;9(2):89-98. 